\title{
What do Big Data do in Global Governance?
}

\author{
Krause Hansen, Hans; Porter, Tony
}

Document Version

Accepted author manuscript

Published in:

Global Governance: A Review of Multilateralism and International Organizations

DOI:

10.1163/19426720-02301004

Publication date:

2017

License

Unspecified

Citation for published version (APA):

Krause Hansen, H., \& Porter, T. (2017). What do Big Data do in Global Governance? Global Governance: A Review of Multilateralism and International Organizations, 23(1), 31-42. https://doi.org/10.1163/1942672002301004

Link to publication in CBS Research Portal

\section{General rights}

Copyright and moral rights for the publications made accessible in the public portal are retained by the authors and/or other copyright owners and it is a condition of accessing publications that users recognise and abide by the legal requirements associated with these rights.

Take down policy

If you believe that this document breaches copyright please contact us (research.lib@cbs.dk) providing details, and we will remove access to the work immediately and investigate your claim. 


\section{What do Big Data do in Global Governance? Hans Krause Hansen and Tony Porter}

Journal article (Accepted manuscript*)

\section{Please cite this article as:}

Krause Hansen, H., \& Porter, T. (2017). What do Big Data do in Global Governance? Global Governance: A Review of Multilateralism and International Organizations, 23(1), 31-42. https://doi.org/10.1163/1942672002301004

\section{DOI: 10.1163/19426720-02301004}

The article has been uploaded in accordance with BRILL's Self-Archiving-Rights Policy: https://brill.com/page/RightsPermissions/rights-and-permissions\#selfarchiving

* This version of the article has been accepted for publication and undergone full peer review but has not been through the copyediting, typesetting, pagination and proofreading process, which may lead to differences between this version and the publisher's final version AKA Version of Record. 


\section{What do Big Data do in Global Governance?}

Two paradoxes associated with Big Data are especially relevant to global governance. First, while promising to increase the capacities of humans in governance and elsewhere, Big Data also involve an increasingly independent role for algorithms, technical artifacts, the internet of things, and other objects, which can reduce the control of human actors. Second, Big Data involve new boundary transgressions as data are brought together from multiple sources, including clicks of web users and data flows from machine sensors, while also creating new boundary conflicts as powerful actors seek to gain advantage by controlling Big Data and excluding competitors. These changes are not just about new data sources for global decisionmakers, but instead signal more profound changes in the character of global governance. Keywords: Big Data, Global Governance.

IN RECENT YEARS SO-CALLED BIG DATA HAVE RECEIVED A GREAT DEAL OF ATTENTION BUT THEIR significance with regard to global governance has received much less. Big Data build on the exponential growth of data from new sources such as internet clicks or machine sensors. They stand in contrast to conventional databases that are most often bounded and managed according to specified standards and for predetermined purposes. Big Data can involve ongoing streams of data that are processed, analyzed, and immediately supplied to users, in contrast to periodic surveys that may take months or years to process. More broadly, three distinctive features of Big Data as compared to more conventional data have been identified: volume, variety and velocity (the " $3 \mathrm{Vs").}{ }^{1}$ 
In this paper we argue that Big Data are especially relevant to global governance in two ways that are quite different than more conventional uses of statistics and other data in international affairs. First, Big Data can create automated forms of governance. With Big Data the human element becomes more entangled with and secondary to the non-human objects that are involved, such as computers, software and other technological artifacts. Big Data significantly increase the importance of algorithms for producing, managing and using the data, as compared to smaller databases. Big Data is closely related to the "internet of things" and its direct object-to-object communication. The dominance of non-human objects in Big Data is relevant to global governance because these objects and their materiality stretch across national borders in ways that differ sharply from the relationships between humans and objects associated with more conventional international relations. The spaces between nation-states are not empty. Big Data rely on new media to operate globally, reinforcing, extending, obscuring, and confounding power in new ways. It is important to understand these changes in power relations as Big Data expand in an increasing number of international issue areas.

Second, and related to this, Big Data are associated with new boundary issues that are not primarily territorial, but rather about access to and control of data, creating complicated new conflicts and exclusions globally. With Big Data, the clicks of web-users may be collected and assembled into databases and put together with other sources of data, and made ready for multiple uses not initially imagined by those who have generated and assembled them. The promise of Big Data involves bringing together previously separate flows of data coming from potentially everywhere on the planet. This new development has implications for especially national borders. It also has consequences for the construction of new boundaries, specifically between those whose data are included and those whose are excluded, and between those who 
have access to the data and those who do not. States and private corporations require the boundaries that enable exclusive control or rights over some part of Big Data, even if they also depend on erasing boundaries, including national ones, which hinder the assembly of the data.

In the remainder of this article we start with a conceptual discussion of these two features of Big Data before examining each feature in more detail. We conclude by pointing to the need in future research on the role of Big Data in global governance to investigate in more detail the largely invisible power of those whose create and mobilize Big Data, including their taken-forgranted automated infrastructures, and the potential for less powerful actors to develop and exploit Big Data for their own purposes.

\section{Conceptualizing Big Data and their Paradoxes}

Much like the early discussions on the societal impact of information and communication technologies, such as the internet, current debates about Big Data reflect both utopian and dystopian elements, just as they include some foundational myths about data and scientific practice. ${ }^{2}$ Big Data are also ridden with paradoxes, and discussing these briefly is relevant for our purpose here. Richards and King, ${ }^{3}$ for example, have highlighted three paradoxes of Big Data, transparency, identity and power. First, Big Data seem to make the world more transparent and potentially more predictable. However, the machine-driven production of data, and the tools and techniques to make sense of them, are created by highly specialized people working in relatively closed government or commercial organizations and with methods that are not open to traditional scientific scrutiny. ${ }^{4}$ Second, as the world is apparently made more transparent through Big Data it also becomes possible to identify processes and people in new ways, creating desirable new opportunities and possibilities for avoiding unpleasant risks. 
However, individual or collective identity and privacy can also be threatened. ${ }^{5}$ Third, there is a power paradox. Increased transparency suggests that Big Data can be an accountability tool for the less powerful. Nonetheless, the logistic and physical infrastructure that enable Big Data, the ownership and control over it and the resources of knowledge produced by Big Data, together with the continuous cultivation and uneven distribution of relevant technical expertise, create an "asymmetric relationship between those who collect, store, and mine large quantities of data, and those whom data collection targets."

To Richards and King's three paradoxes of Big Data we would like to add two more: the paradox of objects and the paradox of boundaries. Our two paradoxes are based on insights from affordance and new medium theory, as well as actor-network theory, ANT, including more broadly Science and Technology Studies (STS). These help address relationships between humans and objects, as well as the boundaries and boundary drawing processes so central to the emerging fabric of global governance and the use of Big Data.

Affordance and new medium theories ${ }^{7}$ are relevant to consider because they suggest that sophisticated media technologies, a sine qua non for Big Data, create fields of potential action that can respectively enlarge and restrict social interactions. The transformation of basic information into knowledge is seen as strongly dependent on technologies such as computers and software. These are never "neutral" but always impose certain constraints on the nature and type of possible human communications, while facilitating other types. Technologies have material affordances, i.e. physical properties, which "invite" people to use them in specific ways. For example, the affordances of digital information becomes evident when the information one can smoothly write and send by email is instead written on a piece of paper, put into an envelope and 
send by snail mail. Speed and space matter in the dissemination and reuse of information and have implications for the scope of social relationships. ${ }^{8}$

Affordance and new medium theory offers a useful first step to theorize the linkages and co-constitutive dynamics between humans and material objects, but at the level of social practices and networks ANT and STS have more to offer. ANT and STS, much like affordance and new medium theory, suggest a relatively autonomous role for objects. But unlike affordance and medium theory, this literature focuses on the entanglement of humans with non-human objects in social practices and socio-technical networks. ${ }^{9}$ Entanglement is not smooth, but replete with controversies as information travels along socio-technical networks. Once these controversies are settled, the new objects produced are naturalized. The relatively autonomous qualities of objects in socio-technical networks, and their potential naturalization, do not mean that they operate independently of human actors. Importantly, the autonomy of objects can obscure the power of those who created the objects initially, or of those who can use them to bolster their own power, or of those who can deploy the information produced to extend their power into other areas. ${ }^{10}$

The paradox of objects is that Big Data involve a growth in humans' distinctive cognitive capacities to learn and analyze but also a growing preeminence of quite autonomous objects, which displace and sometimes work against human cognitive capacities. While these machinedriven processes are ultimately fabricated and powered by humans, the processes make in some sense human agency itself secondary, just as their relatively autonomous and increasingly naturalized character tend to make the powers at work invisible.

A fifth paradox we label the paradox of boundaries. This paradox is that Big Data involve a demand for greater openness to enable the acquisition of data and the deployment of their 
effects, but also new boundaries to enable the exercise of control or the making of money. The new technological systems and the constant (auto) updating of algorithms help to create informational networks across established boundaries, including between the national and international, the public and private, and between the past, present and future. Big Data depend on erasing boundaries, including national ones that hinder the assembly of the data. However, those who manage Big Data work through states and private corporations to create new and stronger boundaries to deploy Big Data as a form of control or to create commercializable rights over some part of Big Data. In the next section we focus in more detail on the paradoxes of objects and boundaries associated with the advent of Big Data, and we discuss their relevance for global governance.

\section{Big Data and Global Governance}

In older models of international governance only states and their possessions (such as territory, population, weapons) had significant material presence, with the international spaces between states characterized as empty and anarchic, or as populated by ephemeral, fragile and ineffective norms and international organizations and laws. Global governance, in contrast, involves a rich and dense set of connections that span borders. These include norms, political rationalities, cultures and ideologies, as well as material objects such as paper documents, electronic systems, physical geographies, and many others. The "practice turn" in international relations theory has

emphasized the fusing of ideas and materiality in transnational practices. ${ }^{11}$ The sheer complexity of global governance and the distance between the humans involved means that human relations must be mediated. While applying calculative technologies to human relations, for example in shape of the census and national statistics, and later international statistics, have often reinforced 
national boundaries, Big Data relies more heavily on the capacities of objects, specifically digital technologies, automation and algorithms, and has a different relationship to boundaries. In this section we examine the significance of each of these for transnational governance.

\section{Big Data, Objects and Global Governance}

Big Data is complementary to the development of dense relations across borders. It involves enormously rich sets of connections that can be very autonomous from individual human actors. Data may be generated quite autonomously of human intention, as with sensors, data exhaust from internet clicks, point of sale data, and RFID signals. As of $201361.5 \%$ of internet traffic was carried out by bots rather than humans. ${ }^{12}$ Since 2008 the number of things connected to the internet have exceeded the number of people on earth. ${ }^{13}$ The Internet of Things is estimated to generate more than 400 zetabytes of data by 2018 , which will be more than 50 times the amount of traffic in data centres. ${ }^{14}$ The initial human role in designing such systems may diminish in significance as they begin operating more routinely, and the data generated is deployed in ways not initially imagined. Algorithms and other forms of artificial intelligence may further displace the importance of human agency, as they automatically develop new governance practices.

The autonomous qualities of Big Data do not mean that they then become a technical system that operates independently of power. On the contrary, the autonomy can obscure the power of those who create the systems initially, consistent with the paradoxes discussed earlier, including who can intervene at their discretion to re-calibrate them, who can use them to reinforce and leverage their power, or who can use the information generated to extend their

power into new spaces. Big Data systems have an evolving reflexivity that, when harnessed by powerful actors, can dramatically amplify their power, such as in the cases of state surveillance 
of terrorist suspects or MNCs effectively assessing and harnessing market opportunities, and consumption trends and profiles. Big Data may constitute new powerful actors relatively independently of those actors' own efforts or intentions, such as when a tech start-up suddenly becomes a dominant actor in a new market segment. Big Data's relatively open and reflexive architecture can also provide new opportunities for less powerful actors to exercise agency, for instance when citizens use environmental sensors linked to mobile phones to detect toxic emissions, when consumers trade loyalty cards to conceal their personal information from powerful actors, or when citizens create web platforms that crowd source reports on bribes, which makes it possible to track and publish sites and trends in bribery and corruption. ${ }^{15}$

How globalized are the above types of connections associated with Big Data? Some of the sources of Big Data can provide some indicators, which usefully caution us against overstating the global character of Big Data. For instance international internet traffic is about $17 \%$ of total internet traffic, and an estimated 16 percent of Facebook friends live in different countries. ${ }^{16}$ These indicators understate the global character of Big Data however. For example, major corporations such as Google can aggregate data from the different markets they operate within and apply lessons from one market to another. ${ }^{17}$ In $201052 \%$ of Google's revenue came from international markets. ${ }^{18}$ More than 82 percent of Facebook's users accessed it from outside the US and Canada in 2012, and it is available in 70 languages with sales offices in more than 20 countries. ${ }^{19}$ The infrastructures for cross-border Big Data traffic are rapidly being put in place. ${ }^{20}$

What do the above developments mean for the operation of power in global governance? First, as a cautionary note with regard to the celebratory hype often associated with Big Data, they are harnessed by existing powerful actors to reinforce their own power and the institutional arrangements which sustain this. This includes states, as with the NSA's surveillance, but also 
firms such as Google or IBM. Bhushan has argued that Big Data will be a "disruptive innovation" in international affairs, because it will challenge senior policymakers who are resistant to change.

However many of the examples he provides are closely associated with existing states or international institutions, including the use of Big Data by central banks; the Japanese government's efforts to use Big Data to assess the effects of policy; the UN Global Pulse initiative to measure bread prices; and the World Bank's Listening to Latin America efforts to use mobile platforms to conduct household surveys. $^{21}$

Second, Big Data can nevertheless create and reinforce newer configurations of transnational power, especially private and technical ones. This is especially evident where algorithms directly regulate and enforce conduct. ${ }^{22}$ Like governments, algorithms can integrate, amplify, mobilize, represent, and act in the name of individuals, constituted as publics. For instance, Google is the dominant gateway for accessing the internet, processing 91 percent of searches globally in 2011, and 97.4 percent of mobile searches. ${ }^{23}$ Google Search's effects are produced by the interaction of its algorithms with the individuals that use it to search. Google plays a global governance role in excluding or marginalizing certain websites in searches, such as ones which are likely fraudulent or pornographic, ${ }^{24}$ but also, allegedly, competitors. ${ }^{25}$ Google also enforces copyright by removing search results which link to material that is alleged to be an infringement by content owners. ${ }^{26}$ In the month ending December 30, 2014 Google had received requests to remove more than 36 million urls. ${ }^{27}$ Google removes almost all of these ${ }^{28}$ and this suggests that they are making use of an algorithm. ${ }^{29}$ This suppresses or regulates certain actors and more generally shapes global publics. ${ }^{30}$ Searching, as a practice, increasingly shapes how we experience our world, naturalizing results while concealing the influence of coders on them. ${ }^{31}$ 
The search results it displays appear beside the tailored ads it generates, providing a commercial tone to this public. ${ }^{32}$ Amazon's algorithms that shape reading preferences play a similar role. ${ }^{33}$ Reputational ranking systems such as those associated with eBay, ${ }^{34}$ hotels.com, or AirBnB combine user responses with algorithmic regulation. ${ }^{35}$

The above examples of algorithmic regulation all involve the control of flows of information and suggest more direct automated regulation of physical objects and human bodies, although this is only in the early stages. For instance the insurance industry is already moving towards real-time adjustment of premiums in response to the behavior of the insured, creating immediate financial penalties and a form of effective algorithmic governance. ${ }^{36}$ In the fight against diseases like Ebola, mobile devices like mobile phones can be key, not only helping people to send and coordinating information about outbreaks, but also because of the call-data records (CDR) they produce, including a caller's identity, number, place and time of call. Analysis of those data might help epidemiologists track the spread of diseases. But getting access to the data involves complex political and regulatory issues at national and international levels. ${ }^{37}$

Third, Big Data are beginning to create the capacity for the automation of the production of words and meaning. For instance, there are efforts to assess personalities of customers accessing call centres by developing algorithms capable of distinguishing personality types by analyzing word patterns using voice recognition. ${ }^{38}$ More generally, the innovations and visions associated with the "semantic web," "metadata" and "data ontologies" imagine adding layers of data about data, to provide context and meaning. A widely discussed vision of the semantic web was set out by Tim Berners-Lee, known as the inventor of the internet, and his coauthors, in $2001 .{ }^{39}$ The semantic web would enable computers to contextualize data and to integrate video and other 
material that previously would not be amenable to automated processing. There are severe doubts about the feasibility of this vision but certain elements of it, or comparable initiatives, are slowly developing. ${ }^{40}$ As the capacity of computers to understand meaning increases, they are also displaying increased capacity for writing. ${ }^{41}$ In short, Big Data are increasing opportunities for automated governance.

Overall then, the growing cross-border significance of Big Data links knowledge, humans, and objects in novel ways that differ starkly from traditional state-centric models of international relations. This should not be overstated. Many Big Data applications remain visions or tentative experiments, or local, and they provide zones of connectedness and new power relations that are interwoven with more traditional institutions. Nevertheless, the role of Big Data in transnational governance is already significant, and it is important to understand the distinctive ways that the transnational operations of power are altered as objects are empowered relative to humans.

\section{Big Data, Boundaries, and Global Governance}

With Big Data the following three somewhat contradictory issues associated with national borders are especially important. First, for Big Data to achieve the potential envisioned by its advocates it needs to operate across borders, bringing together data from diverse jurisdictions and deploying the associated effects transnationally. Second, economically Big Data can be seen as the type of strategic infrastructure which national governments traditionally have invested in, in part due to their distinctive capacities to support such infrastructures as compared to firms, and in part due to their interests in competing with other national economies, working against globalizing tendencies. Third, Big Data creates challenges for national cultural and legal practices, especially with regard to privacy and state security, which can lead to "data 
nationalism."42 Governmental management of the above tensions has been carried out through international organizations, multilateral, plurilateral and bilateral negotiations, unilateral actions, and deliberate or tacit decisions to leave them to private and technical actors to resolve.

A key site for resolving the above tensions has been the OECD and discussions associated with its 1980 Guidelines on the Protection of Privacy and Transborder Flows of Personal Data. The OECD Guidelines sought to facilitate interoperability across computer technologies as inconsistent national privacy laws were being enacted. ${ }^{43}$ They reflected and reinforced the emerging consensus on a "notice and consent" approach to data privacy. This required the explicit consent of the individuals' whose data was being collected, the restriction of the use of the data to the purposes stated in that consent process, and the destruction of data once that purpose was fulfilled. ${ }^{44}$ Currently there are efforts to revise these in response to a number of pressures. One estimate is that reading the privacy policies of just the most popular websites would take more than 30 days per year. ${ }^{45}$ As well, Big Data can involve unexpected real-time new uses of data that consent forms could not anticipate. Accordingly the emerging new model is to shift the emphasis away from individual consent to greater accountability of those using the data for privacy protection, and for ensuring appropriately positive benefit/harm ratios. ${ }^{46}$

A key conflict is between the EU and US approaches to data protection. ${ }^{47}$ Certain states are aggressively excluding Google and other internet companies from operating within their territory, such as China, Russia, Turkey. Even OECD countries that favor the relatively free flows of information across borders that are required by many Big Data applications are also often investing in national data infrastructures that display minimal attention to cross-border collaboration. Some countries have government procurement preferences for local digital firms, require local content, or require local storage of data. ${ }^{48}$ 
Intersecting with these more traditional boundary issues are newer boundary issues that are more associated with private and technical authority than state authority. A key tension is between the need for many Big Data projects to extend their reach across different sources and uses of data and the commercial impulse to exclude other actors in the market from access to knowledge about the data or the process for managing it, including consumers and other suppliers of data, devices, and competing firms. Intellectual property laws are one element in this tension. There are numerous other barriers that firms can create that have similar effects to IP laws, including control of key infrastructures or proprietary code needed to access new markets, tying customers of a firm to that firm's other products, excluding competitors from joint ventures where new technologies are being developed. Network effects, where each added participant increases value to all existing participants, can be exploited by firms who are the first to create new networks. ${ }^{49}$ In privacy protection private and technical actors are playing the key boundary setting roles, with terms of use of websites or internet services; the coding and what it makes open or closed; and the organizational boundaries of firms and projects, and how they are reinforced.

The seemingly boundless character of a Google search is misleading not only because of the boundaries that Google creates, as discussed above, but because it reaches only the small part of the web that is open. It has been estimated that less than two percent of online material is publicly accessible, about 65 billion pages, with an additional 9 trillion pages in the "private web" (such as corporate intranets and subscription services) and 18 trillion pages in the "deep web" (large data repositories with unique search and access procedures). ${ }^{50}$ Open Text, from which this estimate comes, is one of the companies that specialize in creating and managing the private and technical boundaries that govern the non-public web. There are countless other 
reasons for boundaries in addition to intellectual property, competition, and privacy, which have been mentioned so far, including regulatory compliance, the management of regulatory and litigation risk, and the stability of data and the organizations associated with them. Open Text has estimated that there are more than 100,000 rules and regulations worldwide that are relevant to records management and Big Data, including country specific ones, industry and country specific ones, international ones, and international industry specific ones. Therefore the ongoing contestations over privacy at the edges of new Big Data technologies are only a small part of the overall struggles and relatively settled sets of rules.

\section{Conclusions}

Big Data highlight new ways that transnational relations is being reshaped by hybrid arrangements of humans and objects and by new boundaries. Big Data create paradoxes of objects and boundaries. On the one hand, the non-human objects created by humans challenge the capacities that Big Data are supposed to enhance. Humans are being entangled in wider socio-technical networks in which information is being translated across established boundaries, including between the national and international, the public and private. At the same time, the predominance of non-human objects including the automation processes relating to Big Data tends to make the agency and power of those who create the systems initially, and of those who use them to reinforce and leverage their power, largely opaque and invisible. More than this, these processes are themselves subject to new boundary drawing and regulation, where traditional and new actors, including private and technical expertise and authority, play important roles, provoking new conflicts and exclusions. The struggles over who has control or 
rights over Big Data, suggest ambiguous tensions between an aspiration to erase boundaries, including national ones that hinder the assembly of the data, and establishing new ones.

Future research on Big Data in global governance should address the intersections of private, public and technical authority in more detail. And in relation to this: because Big Data become even more entangled in the knowledge production and circuits that are central to global governance, and as new boundary issues emerge with the spread of Big Data analytics, the potential for less powerful actors to develop and exploit Big Data for their own purposes should be more systematically analyzed.

${ }^{1}$ See "Big Data: Seizing Opportunities, Preserving Values," Executive Office of the [US] President, Washington, May 2014, p. 4.

2 Dana Boyd and Kate Crawford, "Critical Questions for Big Data," Information, Communication \& Society 15, no. 5 (2012): 662-679.

${ }^{3}$ Jonathan King and Neil M. Richards, "Three Paradoxes of Big Data," Stanford Law Review Online 41, September 3 (2013): 41-46.

${ }^{4}$ Chris Anderson, "The End of Theory: The Data Deluge Makes the Scientific Method Obsolete,"WIRED, 23 June 2008, http://archive.wired.com/science/discoveries/magazine/1607/pb_theory/. For critical discussions see Antoinette Rouvroy, "Technology, virtuality and utopia: governmentality in an age of autonomic computing," in Mireille Hildebrandt and Antoinette Rouvroy, eds., Law, Human Agency and Autonomic Computing (London: Routledge, 2011), pp. 119-140.

${ }^{5}$ David Lyon, "Surveillance, Snowden, and Big Data: Capacities, consequences, critique," Big 
Data \& Society July-December, (2014): 1-13; Mark Andrejevic and Kelly Gates, "Big Data Surveillance: Introduction," Surveillance \& Society 12, no. 2 (2014): 185-196.

${ }^{6}$ Mark Andrejevic, “The Big Data Divide,” International Journal of Communication 8, (2014): 1673-1669.

${ }^{7}$ Ronald J. Deibert, Parchment, Printing, and Hypermedia: Communication in World Order Transformation (New York: Columbia University Press, 1997); Leah A. Lievrouw, "Materiality and Media in Communication and Technology Studies: An Unfinished Project," in Tarleton Gillespie, Pablo J. Boczkowski, and Kirsten A. Foot, eds., Media Technologies. Essays on Communication, Materiality, and Society (Cambridge, Mass.: MIT Press, 2014), pp. 21-52.

${ }^{8}$ Leah A. Lievrouw, "Materiality and Media in Communication and Technology Studies: An Unfinished Project," in Tarleton Gillespie, Pablo J. Boczkowski and Kirsten A. Foot, eds., Media Technologies. Essays on Communication, Materiality, and Society (Cambridge, Mass.: MIT Press, 2014), pp. 21-52.

${ }^{9}$ Bruno Latour, Reassembling the social: An introduction to actor-network-theory (Oxford: Oxford University Press 2005); Gavin Kendall, “Global networks, international networks, actor networks," in Wendy Larner and William Walters, eds., Global Governmentality. Governing International Spaces (London: Routledge, 2004), pp. 59-75.

${ }^{10}$ For more detailed conceptualizations and empirical investigations with a specific focus on these issues in transnational governance, see Tony Porter, "Making serious measures: numerical indices, peer review, and transnational actor-networks," Journal of International Relations and Development 15, no. 3 (2012): 532-557; Hans K. Hansen and Tony Porter, "What do Numbers do in Transnational Governance,” International Political Sociology 6, no. 4 (2012): 409-426. 
${ }^{11}$ Emanuel Adler and Vincent Pouliot, International Practices (Cambridge: Cambridge University Press, 2011).

${ }^{12}$ Alexis C. Madrigal, "Welcome to the Internet of Thingies: $61.5 \%$ of Web Traffic is not Human,” The Atlantic, 12 December 2013, http://www.theatlantic.com/technology/archive/2013/12/welcome-to-the-internet-of-thingies615-of-web-traffic-is-not-human/282309/.

13 "ciscoinfographic," All Things D, 14 July 2011, http://allthingsd.com/20110714/ciscoreminds-us-once-again-how-big-the-internet-is-and-how-big-its-getting/ciscoinfographic/; Dave Evans, "The Internet of Everything," (2012), http://www.cisco.com/web/about/ac79/docs/innov/IoE.pdf. Evans is Cisco's Chief Futurist and Chief Technology Officer.

${ }^{14}$ The figure is from Cisco, which uses the "Internet of Everything" label. "Cisco Global Cloud Index: Forecast and Methodology, 2013-2018," Cloud Index White Paper, (2014), http://www.cisco.com/c/en/us/solutions/collateral/service-provider/global-cloud-indexgci/Cloud_Index_White_Paper.pdf, p. 17.

${ }^{15}$ Gregg P. Macey, “The Architecture of Ignorance," Utah Law Review, no. 6 (2013): 1627-85; Emily Steel, "Consumers Seek a Way to Draw the Veil Back over their Lives," Financial Times, 12 June 2013, http://www.ft.com/cms/s/0/8fa3e528d34311e2b3ff00144feab7de; Finn Brunton and Helen Nissenbaum, "Vernacular resistance to data collection and analysis: A political theory of obfuscation," First Monday 16, no. 5 (2 May 2011), http://firstmonday.org/ojs/index.php/fm/article/view/3493/2955; Tim Davies and Silvana Fumega, "Mixed Incentives: Adopting ICT Innovations for transparency, accountability, and 
anti-corruption," U4 Issue, no. 4 (June 2014), http://www.cmi.no/publications/file/5172-mixedincentives.pdf.

16 Data from Lars Backstrom, Brian Karrer, Cameron Marlow, and Johan Ugander, "The Anatomy of the Facebook Social Graph.” arXiv:1111.4503 [cs.SI], (November 2011), http://arxiv.org/abs/1111.4503. as reported in Steven A. Altma and Panjak Ghemawat, DHL Global Connectedness Index 2014, p. 14.

http://www.dhl.com/content/dam/Campaigns/gci2014/downloads/dhl_gci_2014_study_low.pdf. ${ }^{17}$ As Google Ads states, "There are 2.7 billion Internet users worldwide and tens of millions of businesses online. Wouldn't you like to add them as customers? Google offers powerful marketing tools and free translation tools to help you attract, communicate with, and sell to audiences everywhere in the world." See Google, "Go Global with Google," (2014), http://www.google.com/ads/global/.

${ }^{18}$ Douglas MacMillan, “Google Undergoes Global Growing Pains,” Bloomberg Businessweek, 25 February 2010,

http://www.businessweek.com/technology/content/feb2010/tc20100224_084405.htm.

${ }^{19}$ See "Digital Trade in the US and Global Economies, Part 1," US International Trade Commission, Washington DC, (July 2013), pp. 2-23.

20 Cisco, Cisco Global Cloud Index: Forecast and Methodology, 20132018, (2014), http://www.cisco.com/c/en/us/solutions/collateral/service-provider/global-cloudindex-gci/Cloud_Index_White_Paper.pdf.

${ }^{21}$ Aniket Bhushan, "Fast Data, Slow Policy: Making the Most of Disruptive Innovation," SAIS Review 34 Winter-Spring, no. 1 (2014): 93-107. 
${ }^{22}$ Evgeny Morozov, "The Rise of Data and the Death of Politics," The Guardian, 20 July 2014, http://www.theguardian.com/technology/2014/jul/20/rise-of-data-death-of-politics-evgenymorozov-algorithmic-regulation.

${ }^{23}$ StatCounter data (http://gs.statcounter.com/), as quoted by Ken Hillis, Kylie Jarrett, and Michael Petit, Google and the Culture of Search, (London and New York: Routledge, 2013), p. 3.

${ }^{24}$ Siva Vaidhyanathan, The Googlization of Everything (and why we should worry), (Berkeley and Los Angeles: University of California Press, 2011), p. 14.

${ }^{25}$ See FairSearch.org, a coalition including Microsoft, Oracle, tripadvisor and others, which refers to "growing evidence that Google is abusing its search monopoly to thwart competition," http://www.fairsearch.org/about-fairsearch/, cited in Leonhard Dobusch, "Algorithm Regulation \#5: Regulating Algorithms," Governance Across Borders, 13 April 2013, http://governancexborders.com/2013/04/13/algorithm-regulation-5-regulating-algorithms/\#more3669.

${ }^{26}$ Leonhard Dobusch, “Algorithm Regulation \#2: Negotiating Google Search,” Governance Across Borders, 11 August 2013, http:/governancexborders.com/2012/08/11/algorithmregulation-2-negotiating-google-search/\#more-2836.

${ }^{27}$ Google, “Transparency Report,” (2014), http://www.google.com/transparencyreport/removals/copyright/?hl=en.

${ }^{28}$ Google, “Transparency Report FAQ,” (2014), http://www.google.com/transparencyreport/removals/copyright/faq/\#compliance_reasons. 
${ }^{29}$ Leonhard Dobusch, "New Layer of Copyright Enforcement: Search," Governing across Borders, 28 May 2012, http://governancexborders.com/2012/05/28/new-layer-of-copyrightenforcement-search/. Many of the takedown requests are likely to be bogus, pursued to damage competitors and critics, and even semi-automated. See Electronic Frontier Foundation, "Blacklist Bills Ripe for Abuse, Part I: 'Market-Based Systems," (2011), https://www.eff.org/deeplinks/2011/12/blacklist-bills-ripe-abuse, and EFF, "EFF Calls Foul on Robo-Takedowns," 6 March 2012, https://www.eff.org/press/releases/eff-calls-foul-robotakedowns, both cited by Governing Across Borders, "New Layer."

${ }^{30}$ Francesca Musiani, “Governance by Algorithms," Internet Policy Review 2, no. 3 (2013), http://policyreview.info/articles/analysis/governance-algorithms.

${ }^{31}$ Ken Hillis, Kylie Jarrett, and Michael Petit, Google and the Culture of Search, (New York: Routledge, 2013).

32 Astrid Mager, "Algorithmic Ideology," Information, Communication \& Society 15, no. 5 (2012): pp. 769-787.

${ }^{33}$ Musiani, "Governance by Algorithms.”

${ }^{34}$ Federica Casarosa, “Transnational Private Regulation of the Internet: Different Models of Enforcement," in Fabrizio Cafaggi, ed., Enforcement of Transnational Regulation: Ensuring Compliance in a Global World (Cheltenham: Edward Elgar Publishing Limited, 2012).

35 Tim O'Reilly, “Open Data and Algorithmic Regulation,” in Brett Goldstein with Lauren Dyson, eds., Beyond Transparency: Open Data and the Future of Civic Innovation (San Francisco: Code for America Press, 2013), pp. 289-300. The label "algorithmic regulation" has been credited to O'Reilly. 
${ }^{36}$ Neil Chapman and Colin Towers, "Agile, Real-Time Pricing will put you In Control," TowersWatson, (2015), http://www.towerswatson.com/en-BE/Insights/Newsletters/Global/emphasis/2014/agile-realtime-pricing-will-put-you-in-control.

37 "Ebola and big data," The Economist, 25 October 2014, http://www.economist.com/node/21627557/.

${ }^{38}$ Christopher Steiner, Automate This: How Algorithms Took Over Our Markets, Our Jobs, and the World (New York: Portfolio/Penguin, 2013), p. 182.

${ }^{39}$ Tim Berners-Lee, James Hendler, and Ora Lassila, “The Semantic Web," Scientific American, May 2001, pp. 35-43. On data ontologies see Akram Bou-Ghannam, "Foundational Ontologies for Smarter Industries,” IBM Redpaper, (2013), http://www.ibm.com/redbooks.

${ }^{40}$ World Wide Web Consortium (W3C), "Semantic web," http://www.w3.org/standards/semanticweb/. For the current skepticism about the semantic web see thread at "Is the semantic web still a thing," Hacker News, https://news.ycombinator.com/item?id=8510401.

${ }^{41}$ For instance, one firm, Automated Insights, used algorithms to write over 300 million stories in 2013. Baseball stories draw on sensors, cameras, and historical data. Jeff Bertolucci, "Big Data Learns to Write," Information Week, 2 June 2014, http://www.informationweek.com/bigdata/big-data-analytics/big-data-learns-to-write/d/d-id/1269343.

42 Daniel Castro, "The False Promise of Data Nationalism," The Information Technology \& Innovation Foundation, 9 December 2013. 
${ }^{43}$ Fred H. Cate, Peter Cullen and Viktor Mayer-Schönberger, "Data Protection Principles for the $21^{\text {st }}$ Century: Revising the 1980 OECD Guidelines," (2014).

${ }^{44}$ See "OECD Guidelines on the Protection of Privacy and Transborder Flows of Personal Data," (2013),

Www.oecd.org/internet/ieconomy/oecdguidelinesontheprotectionofprivacyandtransborderflowsof personaldata.htm.

${ }^{45}$ Lorrie F. Cranor, and Aleecia M. McDonald, "The Cost of Reading Privacy Policies," I/S: A Journal of Law and Policy for the Information 4, no. 3 (2008), http://moritzlaw.osu.edu/students/groups/is/files/2012/02/Cranor_Formatted_Final.pdf, cited in Fred H. Cate, Christopher Kuner, Christopher Millard, and Dan J.B. Svantesson, “The challenge of 'big data' for data protection," International Data Privacy Law 2, no. 2 (2012), p. 7.

${ }^{46}$ See Cate, Cullen and Mayer-Schönberger, "Data Protection Principles,” pp. 10-11.

${ }^{47}$ European Commission, "Factsheet EU-US: Negotiations on Data Protection," June 2014, http://ec.europa.eu/justice/data-protection/files/factsheets/umbrella_factsheet_en.pdf.

${ }^{48}$ See "Digital Trade," p. 5-3.

49 These comments rely upon discussion in Gregory G. Wrobel, "Connecting Antitrust Standards to the Internet of Things," Antitrust 29, no. 1 (2014): pp. 62-7.

${ }^{50}$ Tom Jenkins, Behind the Firewall: Big Data and the Hidden Web: The Path to Enterprise Information Management (Waterloo: Open Text Corporation, 2012), p. 14. 